\section{Assessment of pork handlers' knowledge and hygienic status of pig meat shops of Chitwan district focusing campylobacteriosis risk factors}

\author{
Ghimire $\mathrm{L}^{1^{*}}$ Dhakal $\mathrm{S},{ }^{1,2}$ Pandeya $\mathrm{YR},{ }^{1}$ \\ Chaulagain S, ${ }^{1}$ Mahato BR, ${ }^{1}$ Satyal RC, \\ Singh DK ${ }^{1}$
}

${ }^{1}$ Institute of Agriculture and Animal Science (IAAS), Tribhuvan University, Chitwan, Nepal;

${ }^{2}$ National Zoonoses and Food Hygiene Research Centre (NZFHRC), Kathmandu, Nepal

*Corresponding author: Dr. Laxman Ghimire, Institute of Agriculture and Animal Science (IAAS), Tribhuwan University, Rampur, Chitwan, Nepal, email: ghimire.laxman13@gmail.com Tel. No.: (+977)9845198373

\begin{abstract}
INTRODUCTION: Campylobacter causes more cases of diarrhoea than Salmonella and pork is considered as a potential source of Campylobacter infection after poultry. This study aims to assess the butchers' knowledge and hygienic condition of slaughter slabs and retail pork shops of Chitwan district, Nepal focusing campylobacteriosis risk factors.
\end{abstract}

MATERIALS AND METHODS: This study was conducted from September-2012 to December2012. Three sets of semi-structured questionnaires were formed each for slaughter slabs, retail pork shops and pork handlers focusing on butchers' knowledge and hygienic status of pig meat shops. Each of the workers $(n=40)$ of 10 different pork meat shops were interviewed.

RESULTS: Sixty-five percent of the pork handlers were aware about pork borne disease but none of them had heard about campylobacteriosis. Chilling practice was adopted only in $16.7 \%$ of the slaughter slabs. None of them had separate dirty section. Only $30 \%$ of the pork handlers wore apron regularly. None of them wore gloves and masks and $40 \%$ even did not wash hands regularly before and after pork handling. The hygienic practices like sanitation of equipments and regular washing of hands were significantly associated $(\mathrm{p}<0.05)$ with level of education.

CONCLUSIONS: Hygienic condition of pig meat shops of Chitwan is poor which exposes workers as well as meat consumers at risk for campylobacteriosis and other meat borne diseases. Since education was found to affect hygienic practices, awareness generation program focusing pig borne zoonotic diseases seems necessary together with trainings on hygienic meat production and selling techniques.

KEY WORDS: Campylobacteriosis, Risk factors, Knowledge, Slaughter slabs, Pork

Article submitted 20 December 2012. Reviewed 20 January. Author correction 12 February. Final version accepted 27 February 2013. 


\section{INTRODUCTION}

Campylobacter is the leading cause of zoonotic enteric infections in developed and developing countries. ${ }^{1}$ It causes more cases of diarrhoea than Salmonella spp. ${ }^{2} \quad$ Sometimes, extraintestinal manifestation such as Guillain-Barr'e syndrome (GBS), an acute post-infectious ascending paralysis that can affect peripheral and cranial nerves (particularly facial nerve), occurs requiring artificial ventilation in severe cases. ${ }^{3}$ GBS may be the most common cause of acute flaccid paralysis after polio. ${ }^{1}$ Although the poultry industry is principally responsible for human campylobacteriosis, the pork industry has equally been identified as a potential source of human infection. ${ }^{4}$ Pork meat, water, slaughterhouse equipments and intestinal content are considered as risk factors of Campylobacter contamination in pork slaughter slabs. ${ }^{5,6,7,8}$ Pork handlers are frequently exposed to these risk factors during their work.

Data on human campylobacteriosis is sparse in Nepal. In a cohort study carried out in 1999, the annual attack rate of Campylobacter spp. was found to be $10 \%$ in 77 expatriate adults who had lived in Nepal for less than 2 years. ${ }^{9}$ Till date, only few studies have been done in Nepal focusing on hygienic status of slaughter slabs. One of such studies was carried out by Joshi in Kathmandu valley in 1991 reporting poor hygienic condition of slaughter slabs but the study did not focus on campylobacteriosis risk factors. ${ }^{10}$ In this context, this study is carried out to assess the butcher's knowledge and hygienic status of slaughter slabs and retail pork shops of Chitwan district focusing on campylobacteriosis risk factors so as to determine weak points and at the same time, find out possibilities for the future betterment.

\section{MATERIALS AND METHODS}

This cross-sectional study was conducted from September, 2012 to December, 2012 in Chitwan district. There were 10 different pig meat shops (5 slaughter slabs and 5 retail pork shops) in Chitwan district situated at Lions chowk, Lila chowk, Bharatpur, Tandi, Parsa and Sauraha. All of these were selected for the study.

Three sets of semi-structured comprehensive questionnaires were developed each for slaughter slab, retailers and pork handlers. The first set was for slaughter slabs that focused on i) condition of water, ii) sanitization of equipments, iii) slaughterhouse practices and condition and iv) contamination of carcass with intestinal content; the second was for retail shops that focused on i) condition of water, ii) sanitization of equipments and iii) condition of meat shop while the third was for pork handlers focusing on knowledge assessment and safety measures adopted by pork handlers. Each of these questionnaires was pretested upon 12 pork handlers. All of the pig slaughter slabs and retail pork shops were visited and each of the workers of these places was interviewed. Data entry, arrangement and analysis were done by using program Microsoft Excel 2007 and SPSS version 19. The association between different risk factors was analyzed by using Fisher's exact test at $5 \%$ level of significance.

\section{RESULTS}

\section{Assessment of knowledge}

Out of 40 individuals interviewed, 24 were butchers working in 5 different slaughter slabs and 16 were workers of retail pig meat shop. This study revealed that $65 \%(26 / 40)$ of the respondents were aware about pork borne disease but none of them had heard about campylobacteriosis. Furthermore, 25\% $(10 / 40)$ of them were illiterate, $50 \%(20 / 40)$ had primary level education, $15 \%(6 / 40)$ had secondary level education and 10\% (4/40) had got college level education. Among those who had got college level education, $75 \%$ used to clean the slaughtering equipments daily. The habit of sanitation of slaughtering equipments as practiced by workers is shown in percentage comparing with their education level in graph (Figure).

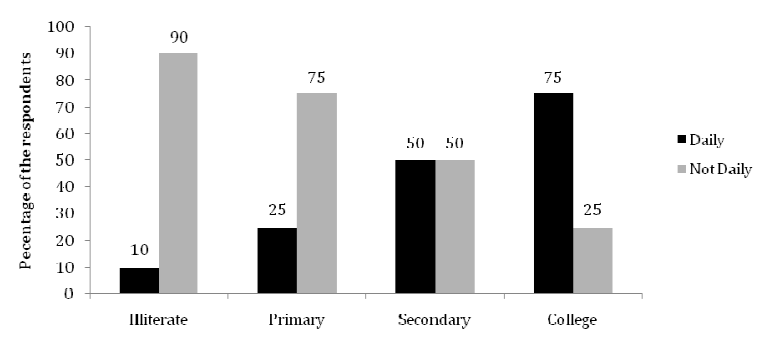

Figure. Sanitation of equipment used in slaughter slabs and retail pork shop

\section{Assessment of hygienic condition of pork meat shops and safety measures adopted}

Out of 10 pig meat shops (5 slaughter slabs and 5 retail shops), $60 \%(6 / 10)$ used tube well as a source of water and $40 \%(4 / 10)$ used tap water. None of them used water purifier to purify water to be used 
Table 1. Hygienic condition of pork meat shops and safety measures adopted by pork handlers

\begin{tabular}{lcc}
\hline Parameters & \multicolumn{2}{c}{ Response } \\
& Yes, $n(\%)$ & No, $n(\%)$ \\
\hline $\begin{array}{l}\text { Butchers response about contamination of carcass with intestinal content during slaughter } \\
(\mathrm{n}=24)\end{array}$ & $16(67)$ & $8(33)$ \\
Butchers response about use of anal plugs during slaughtering $(\mathrm{n}=24)$ & $0(0)$ & $24(100)$ \\
Nuisance of flies in pig meat shops $(\mathrm{n}=10)$ & $8(80)$ & $2(20)$ \\
Slaughter slabs having provision of separate dirty section $(\mathrm{n}=5)$ & $0(0)$ & $5(100)$ \\
\hline Slaughter house practicing chilling of carcass immediately after slaughter $(\mathrm{n}=5)$ & $1(16.7)$ & $4(83.3)$ \\
Workers wearing gloves and masks $(\mathrm{n}=40)$ & $0(0)$ & $40(100)$ \\
Workers wearing apron daily (n=40) & $12(30)$ & $28(70)$ \\
Workers washing hands regularly before and after pork handling $(\mathrm{n}=40)$ & $24(60)$ & $16(40)$ \\
\hline Workers washing hands regularly with soap and water $(\mathrm{n}=24)$ & $20(83)$ & $4(17)$ \\
\hline
\end{tabular}

Table 2. Association of educational level with other parameters

\begin{tabular}{|c|c|c|c|c|}
\hline \multirow{2}{*}{ Particulars } & & \multicolumn{2}{|c|}{ Level of education } & \multirow{2}{*}{${ }^{*} \mathrm{p}$-value } \\
\hline & & Illiterate & Literate & \\
\hline \multirow{2}{*}{$\begin{array}{l}\text { Frequency of sanitization } \\
\text { of equipments }\end{array}$} & Daily & 1 & 14 & \multirow[t]{2}{*}{0.04} \\
\hline & Not daily & 9 & 16 & \\
\hline \multirow[t]{2}{*}{ Frequency of washing hands } & Daily & 2 & 22 & \multirow[t]{2}{*}{0.005} \\
\hline & Not daily & 8 & 8 & \\
\hline \multirow[t]{2}{*}{ Frequency of wearing apron } & Daily & 3 & 9 & \multirow[t]{2}{*}{0.65} \\
\hline & Not daily & 7 & 21 & \\
\hline
\end{tabular}

*Fisher's exact test

in slaughtering process. We tried to find out the reason why they didn't use water purifiers and got to know that much of the butchers $79 \%(19 / 24)$ were ignorant of such things while some $21 \%$ $(5 / 24)$ were having no such practice due to money factor because they thought water purifiers are expensive.

In all the slaughter slabs, slaughtering was done on the rough concrete ground with butchers wearing slippers that frequently contaminated the slaughtering area. Nuisance of flies were found in $80 \%(8 / 10)$ of the pig meat shops. None of the slaughter slabs had separate dirty section. Only $16.7 \%(1 / 5)$ of the slaughter slabs adopted chilling practice immediately after slaughter. About 67\% $(16 / 24)$ of butchers agreed that contamination of intestinal content with carcass occurs often during slaughtering but none of the butchers used anal plug during slaughter.

Only 30\% (12/40) of the pork handlers wore apron regularly. None of them wore gloves and masks. Furthermore, $60 \%(24 / 40)$ of the pork handlers wash hands regularly before and after pork handling while $40 \%(16 / 40)$ do not wash hands regularly. Out of these 24 pork handlers who wash hands regularly, 83\% (20/24) use soap and water while washing hands whereas $17 \%(4 / 24)$ do not use soap during washing hands (Table 1).

\section{Association of level of education with safety measures adopted and sanitary practice}

Level of education was significantly associated with frequency of sanitization of equipments $(p<0.05)$ and washing of hands $(\mathrm{p}<0.05)$ but, no significant difference was found $(p>0.05)$ in apron wearing frequencies between literate and illiterate pork handlers (Table 2).

\section{DISCUSSION}

This study showed that majority of pork handlers were either illiterate or having low level of education. They were unaware of zoonotic diseases like campylobacteriosis. In a study carried out in Ghana in 2011, Adzitey et. al. reported that $64 \%$ of the butchers did not have formal education and, none of them had secondary and college level education. ${ }^{11}$ This is similar to the findings of our study. The hygienic condition of slaughter slabs and retail pork shops was found to be poor in Chitwan district. In one previous study carried out in Kathmandu valley in 1991, similar poor hygienic condition of slaughter slabs were found. ${ }^{10}$ Moreover, slaughtering was done under unsanitary condition over the rough concrete floor. In another 
study carried out in Tanzania in 2010, Mdegela et. al. reported similar condition of slaughtering process where pig slaughter, dressing and meat handling were done on the ground under unsanitary condition. ${ }^{12}$

Water used in sanitation of slaughterhouse and meat shops is potential source of Campylobacter contamination as it allows for cross contamination of carcasses. ${ }^{6}$ In a study conducted by Bhattarai in 2011, campylobacters were found in $10 \%$ of water samples taken from different slaughter slabs of Rupandehi district. ${ }^{13}$ This shows that water from slaughter slabs of Nepal contains sufficient amount of campylobacters to cross contaminate the carcass during slaughtering. Since none of the butchers under this study used water purifier, the chance of cross contamination is high.

Slaughterhouse equipments are also potential source of cross contamination of Campylobacter. ${ }^{7}$ Cleaning the equipments like knives before and after use significantly decreases the contamination rate of Campylobacters. ${ }^{14}$ However, the frequency of sanitization of slaughtering equipment was lower in study area which indicates higher risk of contamination. The frequency of sanitation of slaughtering equipments was increased with the education level of the workers. The anal plug method during slaughter would decrease the chance of contamination of carcass with intestinal content thereby reducing Campylobacter contamination rate. ${ }^{5,14}$ However, none of the butchers were using such practices.

Only $30 \%$ of the pork handlers used to wear apron daily. None of them wore gloves and masks which showed that they were unaware about adequate safety measures needed to be adopted to prevent them from campylobacteriosis and other diseases. None of them having heard about campylobacteriosis and very few knowing about zoonotic diseases also supports this. The level of education of pork handlers was significantly associated with frequency of sanitizing slaughtering equipments and frequency of washing hands before and after pork handling $(\mathrm{p}<0.05)$. This finding has raised the key issue of illiteracy. If more educated people start these industries then there is likeliness of adoption of safety measures and hygienic practices. Besides this, strengthening of knowledge level of current workers about hygienic meat production and awareness generation on safety measures against zoonotic diseases like campylobacteriosis is also necessary and can improve the present scenario.

\section{CONCLUSION}

Poor hygienic condition was found in slaughter slabs and retail pork shops of Chitwan district. Considering the inability of government to implement Meat Inspection and Slaughter House Act (1999), these findings can be taken as the representative of other meat shops of the country as well. The workers at slaughter houses and retail meat shops as well as the consumers are equally at high risk of zoonotic diseases like campylobacteriosis and other owing to the present scenario. Since education and awareness can be effective in improving the behavior and practices at slaughter houses and retail meat shops, awareness generation programs focusing campylobacteriosis and other zoonotic diseases are recommended.

CONFLICT OF INTEREST: None to declare.

FINANCIAL INTEREST: None to declare.

\section{REFERENCES}

1. WHO/CDS/CSR/APH. The increasing incidence of human campylobacteriosis, report and proceedings of a WHO consultation of experts. Copenhagen, Denmark 2000.

2. Schrotz-King P, Prokhorova TA, Nielsen PN, Crawford JS, Morsczeck C. Campylobacter jejuni proteomics for new travelers' diarrhoea vaccines. Travel Med Infect Dis 2007;5:106-109.

3. Kuwabara S. Guillain-barre syndrome. Curr Neurol Neurosci Rep 2007;7:57-62.

4. Allos BM. Campylobacter jejuni infections: update on emerging issues and trends. Clin Infect Dis 2001;32:12011206.

5. Abley M J, Wittum TE, Moeller SJ, Zerby HN, Funk JA. Quantification of Campylobacter in swine before, during and after slaughter process. J Food Prot 2012;75:139-43.

6. Diegaardt S M, Venter SN, Spreeth A, Theron J, Brozel VS. The occurance of Campylobacter in water sources in South Africa. Water Res. 2004;38:2589-2595.

7. Pearce, R.A., Wallace FM, Call JE, et al. Prevalence of Campylobacter within a swine slaughter and processing facility. J Food Prot 2003;66:1550-1556.

8. Gillespie IA, O'Brien SJ, Frost JA, et al. The Campylobacter sentinel surveillance scheme collaborators. A case-case comparison of Campylobacter coli and Campylobacter jejuni Infection: a tool for generating hypotheses. Emerg Infect Dis 2002;8:937-942.

9. Shlim DR, Hoge CE, Rajah R, Scott RM, Pandy $P$, Echeverria P. Persistent high risk of diarrhea among foreigners in Nepal during the first 2 years of residence. Clin Infect Dis. 1999;29:613-6. 
10. Joshi DD. Current practices of livestock slaughtering and meat marketing in Kathmandu, Lalitpur and Bhaktapur. Kathmandu; Nepal; Zoonoses and Food Hygiene Research Center; 1991.

11. Adzitey F, Teye GA, Dinko MM. Pre and postslaughter animal handling by butchers in the Bawku Municipality of the Upper East Region of Ghana. Livestock Research for Rural Development 2011. Accessed December 15, 2013, from http://www.lrrd.org/lrrd23/2/ adzi23039.htm.

12. Mdegela RH, Laurence $K$, Jacob $P$, Nonga HE. Occurance of thermophilic Campylobacter in pigs slaughtered at Morogoro slaughter slab, Tanzania. Trop Anim Health Prod 2010;43:83-87.

13. Bhattarai DB. Prevalence of Campylobacter isolated from water. Germany: Lambert Academic Publishing;2011.

14. Chaichin S, Chaveerach P, Pimpukdee K. Risk factors of Campylobacter contamination in pig carcass from slaughterhouse. Khon Kaen Uni Vet J 2010;20:178-187.

\section{Citing this article}

Ghimire L, Dhakal S, Pandeya YR, et al. Assessment of pork handlers' knowledge and hygienic status of pig meat shops of Chitwan district focusing campylobacteriosis risk factors. Int J Infect Microbial 2013;2(1);17-21. 